\title{
Tbr2-positive intermediate (basal) neuronal progenitors safeguard cerebral cortex expansion by controlling amplification of pallial glutamatergic neurons and attraction of subpallial GABAergic interneurons
}

\author{
Alessandro Sessa, ${ }^{1}$ Chai-An Mao, ${ }^{2}$ Gaia Colasante, ${ }^{1}$ Alessandro Nini,${ }^{1}$ William H. Klein, ${ }^{2}$ \\ and Vania Broccoli ${ }^{1,3}$ \\ ${ }^{1}$ Stem Cells and Neurogenesis Unit, Division of Neuroscience, San Raffaele Scientific Institute, Milan 20132, Italy; ${ }^{2}$ Department \\ of Biochemistry and Molecular Biology, The University of Texas M.D. Anderson Cancer Center, Houston, Texas 77030, USA
}

Little is known about how, during its formidable expansion in development and evolution, the cerebral cortex is able to maintain the correct balance between excitatory and inhibitory neurons. In fact, while the former are born within the cortical primordium, the latter originate outward in the ventral pallium. Therefore, it remains to be addressed how these two neuronal populations might coordinate their relative amounts in order to build a functional cortical network. Here, we show that Tbr2-positive cortical intermediate (basal) neuronal progenitors (INPs) dictate the migratory route and control the amount of subpallial GABAergic interneurons in the subventricular zone (SVZ) through a non-cell-autonomous mechanism. In fact, Tbr2 interneuron attractive activity is moderated by Cxcl12 chemokine signaling, whose forced expression in the Tbr2 mutants can rescue, to some extent, SVZ cell migration. We thus propose that INPs are able to control simultaneously the increase of glutamatergic and GABAergic neuronal pools, thereby creating a simple way to intrinsically balance their relative accumulation.

[Keywords: Intermediate neural progenitors; basal progenitors; neurogenesis; cerebral cortex; cell migration; interneurons]

Supplemental material is available at http://www.genesdev.org.

Received January 18, 2010; revised version accepted June 21, 2010.

The overall ratio of glutamatergic projection neurons to GABAergic local interneurons is critical to maintain the functional integrity of the cerebral cortex. In fact, an altered balance between these two populations might result in death or lead to a large variety of neurological symptoms ranging from untreatable epilepsy to psychiatric disorders (Powell et al. 2003; Kalanithi et al. 2005; Kitamura et al. 2009; Belforte et al. 2010). During development of the mammalian brain, the cerebral cortex undergoes enormous expansion, yet nevertheless preserves the right balance between excitatory and inhibitory neurons. In particular, it has been difficult to reconcile how this ratio is maintained, considering the independent

${ }^{3}$ Corresponding author.

E-MAIL broccoli.vania@hsr.it; FAX 39-02-26434621.

Article is online at http://www.genesdev.org/cgi/doi/10.1101/gad.575410. sites of origin of these two neuronal cell types. In rodents, while the glutamatergic neurons originate from cortical progenitors (Molyneaux et al. 2007), the GABAergic interneurons are first specified in the medial ganglionic eminence (MGE) of the ventral telencephalon (subpallium), and only subsequently invade the cerebral cortex through a long-distance migration using two well-defined tangential routes located in the marginal zone (MZ) and the subventricular zone/intermediate zone (SVZ/IZ) (Marin and Rubenstein 2001; Polleux et al. 2002; Wonders and Anderson 2006; Batista-Brito and Fishell 2009). However, it is unknown whether mechanisms exist to regulate the number of inhibitory interneurons with respect to the overall amount of excitatory neurons.

Recently, we and others reported that the genetic ablation of Tbr2 in the telencephalon dramatically reduces intermediate neuronal progenitors (INPs), a class of cortical progenitors derived by radial glial cells, which divide 
symmetrically once or twice in the basal (abventricular) region of the SVZ (Arnold et al. 2008; Sessa et al. 2008). INPs are a characteristic feature of mammals, and, during evolution, increased INPs are believed to promote expansion of the cerebral cortex and its excitatory neuronal pool (Götz and Huttner 2005; Kriegstein et al. 2006; Farkas and Huttner 2008). The Tbr2 mutant cortex is severely affected, and all its cortical layers are reduced in thickness, confirming that INPs are necessary to expand the pool of glutamatergic neurons within each single cortical layer (Sessa et al. 2008; Kowalczyk et al. 2009). More recently, two more master regulators of INP biogenesis-namely, Insm1 (insulinoma-associated 1) and AP2 $\gamma$ (Tcfap2c)-have been identified (Farkas et al. 2008; Pinto et al. 2009). Insm1, despite its general role as a pan-neurogenic factor throughout the brain, promotes formation and sustains self-amplification of INPs within the cerebral cortex (Farkas et al. 2008). In contrast, AP2 $\gamma$ regulates the transition between radial glia cells and INPs, and its inactivation leads to INP misspecification and consequent cell death (Pinto et al. 2009). Interestingly, this INP loss is restricted to the caudal but not frontal cortical regions, indicating the existence of different transcriptional networks that provide a regionand time-specific control of INP biogenesis in various cortical areas, with AP2 $\gamma$ determining the final output of callosal neurons in the occipital cortex (Pinto et al. 2009). However, among these key molecular players of INP cell fate, a manifested human neurological syndrome has been associated with Tbr2 silencing only. In particular, TBR2 deficiency causes recessive microcephaly, polymicrogyria, corpus callosum agenesis, cognitive defects, and severe motor delay (Baala et al. 2007). Interestingly, mouse Tbr2 mutant brains have similar deficits, strongly suggesting that Tbr2 function in regulating INP formation and proliferation has been conserved throughout animal evolution. Since INPs function in amplifying the pool of glutamatergic neurons, it remains unclear how cortical GABAergic interneurons might cope with this severe neuronal loss and its dependent reduction in excitatory activity. This question is particularly relevant, not only for the Tbr2-dependent microcephaly, but for all those congenic brain malformations where a general or regional alteration in principal cortical neurons is generated.

In this study, we show that $\mathrm{Tbr} 2^{+}$INPs have the ability to attract, by a non-cell-autonomous mechanism mediated in part by Cxcl12 signaling, GABArgic neurons from the ventral telencephalon. Through this mechanism, $\mathrm{Tbr}^{+}$INPs generate an independent route of tangential cell migration within the SVZ of the cerebral cortex. In Tbr2 mutant brains, the deep migration route of the GABAergic neurons is lost, reducing their total amount in the mature cortex, thereby compensating for the loss of INP-derived principal glutamatergic neurons. Thus, Tbr2 ${ }^{+}$INPs are a crucial cellular hub in the developing cortex, and, on one side, directly amplify glutamatergic neurons, while on the other, promote the invasion of interneurons within the cortical plate $(\mathrm{CP})$ through indirect means. In our hypothesis, INPs function as a cellular rheostat for balancing the ratio of both populations of cortical neurons during corticogenesis.

\section{Results}

Since Tbr2 mutant brains display a severe reduction in glutamatergic neuronal production, we wondered whether this impairment could have an impact on the correct establishment of the GABAergic cortical network.

Surprisingly, we noted that, compared with cortices of controls, cortices of Tbr2 mutants ( $\mathrm{Tbr} 2^{\text {floxed/floxed; }}$ FoxG1-Cre) exhibited a striking reduction of Calbindin ${ }^{+}$ GABAergic interneurons, accounting for a general decrease by half of the Calbindin ${ }^{+}$migrating cells in embryonic day 14.5 (E14.5) and E16.5 mutant cortices (Fig. 1A-F).

Interestingly, this reduction in Calbindin ${ }^{+}$cells was associated with a nearly complete loss of the SVZ/IZ tangential migratory route (Fig. 1D,E, arrowheads), whereas the superficial MZ stream was preserved (Fig. 1A-E, arrows). This was confirmed independently by crossing Tbr2 conditional mutants with GAD-65 transgenic mice and mapping the position of $\mathrm{GFP}^{+}$interneurons within the mutant cortices. $\mathrm{GFP}^{+}$cells were excluded by the SVZ cortical domain while present in the MZ with comparable numbers with respect to the wild-type counterpart (Supplemental Fig. S1). Finally, a similar route-specific migratory defect was suggested by the expression of Lhx6 and ErbB4, two molecular markers for interneuron migratory cells, while the distribution of Reelin ${ }^{+}$Cajal-Retzius cells moving into the $\mathrm{MZ}$ pathway was not affected (Supplemental Fig. S2A-F). Interestingly, this loss of subpallial interneurons was strictly associated with a large increase in $\mathrm{Lhx}^{+}$, Calbindin $^{+}$, and Calretinin ${ }^{+}$apoptotic cells located mainly within the ganglionic eminences (Supplemental Fig. S3). These data indicate that, in Tbr2 mutant brains, a consistent fraction of subpallial interneurons failing to migrate within the SVZ/IZ cortical route is selectively lost by induced apoptosis in the ventral telencephalic regions. In contrast, the proliferation index was not found altered in the ganglionic eminences, as assessed by short BrdU incorporation (Supplemental Fig. S3R-T) and phospo-Histone H3 (PH3) immunoreactivity (Supplemental Fig. S3O-Q) labeling of S-phase and M-phase cells, respectively.

To assess how these early migratory defects are translated into the mature cerebral cortices, we analyzed interneuron distribution in perinatal and postnatal Tbr2 mutant brains. We detected an $\sim 55 \%$ reduction in Calbindin-expressing interneurons in both E18.5 and postnatal day 21 (P21) Tbr2 mutants compared with control cortices (Figs. 1G-I, 2). However, this loss was exclusively dependent on the strong decrease of cortical tissue in the mutants, since the general density of Calbindin ${ }^{+}$ interneurons was not changed in both genotypes, as determined by profile counting (Supplemental Fig. S4).

Since cortical interneurons include different subtypes that are classified according to their origin, morphology, and function, we ascertained whether different subgroups of interneurons displayed a similar decrease. As for Calbindin ${ }^{+}$interneurons, Calretinin ${ }^{+}$, Somatostatin ${ }^{+}$, $\mathrm{NPY}^{+}$, and Parvalbumin ${ }^{+}$cortical cells were reduced to a similar extent, but maintained a comparable cell density between mutant and control brains (Fig. 2; Supplemental Fig. S4). 

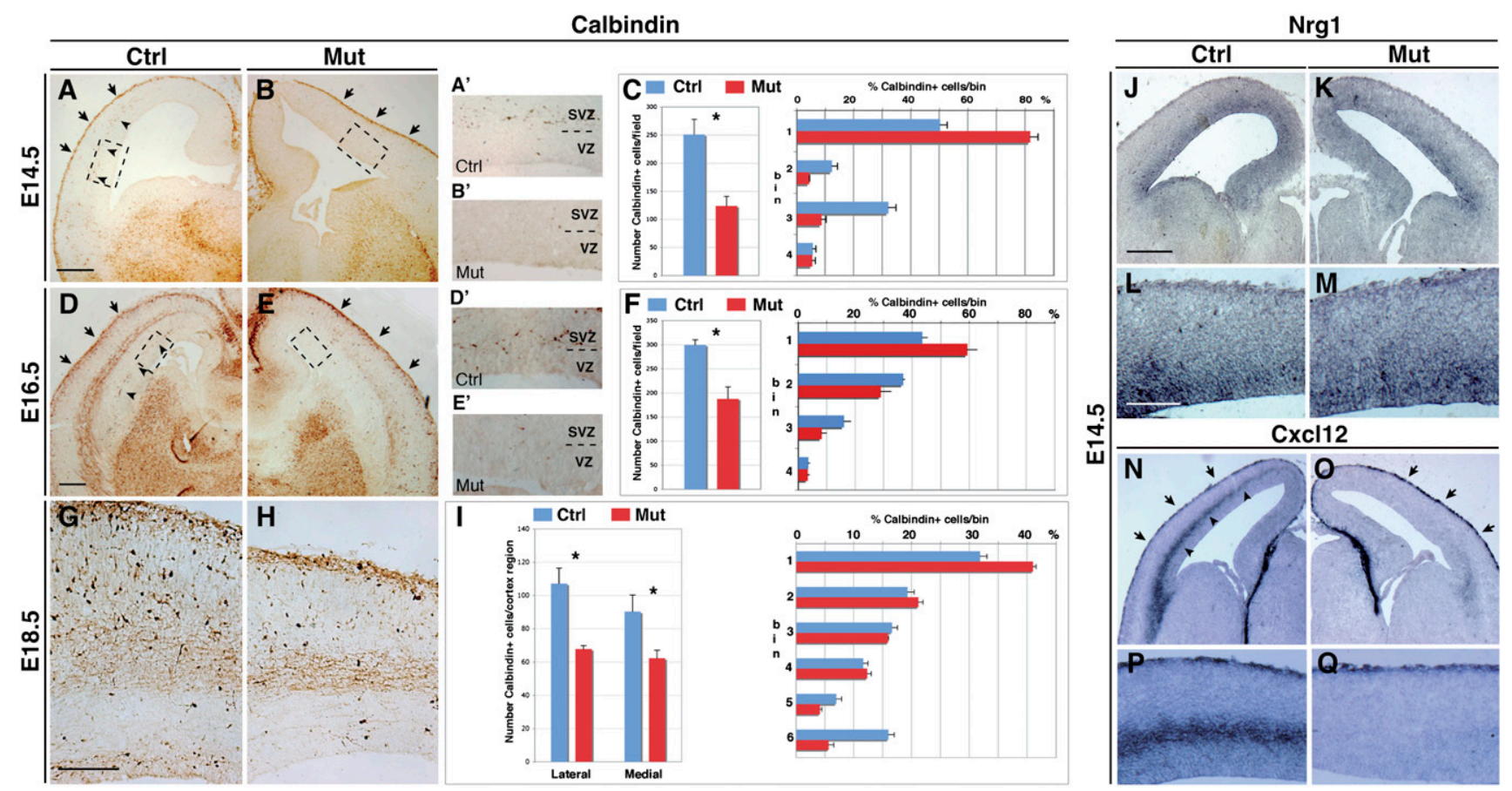

Figure 1. Tbr2-deficient cerebral cortices show specific loss of the interneuron SVZ migrating stream. $(A, B)$ Calbindin ${ }^{+}$cortical interneurons are detected in the MZ (arrows), but not in the SVZ (arrowheads), in E14.5 Tbr2 mutants, as is different from control cerebral cortices. $\left(A^{\prime}, B^{\prime}\right)$ Higher magnifications of the cortical areas outlined in the boxed regions in $A$ and $B$, respectively. $(C)$ Quantification of total Calbindin ${ }^{+}$cells (histograms indicate the total number of positive cells per field \pm SEM: Ctrl, $251 \pm 26.9 ;$ Mut, $123.7 \pm 17$; $t$-test $<$ 0.001 ) and their respective distribution in the cortical wall (numbers in ordinate identify bins for quantification; $t$-test, $P<0.001$; error bars indicate SEM). $(D, E)$ At E16.5, Calbindin ${ }^{+}$interneurons are still migrating through the deep route in the cortical SVZ/IZ in control, but not Tbr2 mutant, cortices. $\left(D^{\prime}, E^{\prime}\right)$ Higher magnifications of the cortical areas outlined in the boxed regions in $D$ and $E$, respectively. $(F)$ Quantification of total positive cells per field ( \pm SEM: Ctrl, $299.7 \pm 10.8$; Mut, $187.7 \pm 24.9$; $t$-test, $P<0.001$ ) and their distribution in the cortical wall (numbers in ordinate identify bins for quantification; $t$-test, $P<0.001$; error bars indicate SEM). $(G, H)$ At 18.5 , Calbindin ${ }^{+}$ GABAergic neurons settled in the cortex are reduced in the mutant with respect to control cortices, although their distribution was not greatly affected. (I) Quantification of the overall number of Calbindin ${ }^{+}$cells $( \pm$SEM: Ctrl lateral, 107.2 \pm 9.3 ; Mut lateral, 67.9 \pm 2.1 ; Ctrl medial, $90.3 \pm 9.9$; Mut medial, $62.3 \pm 4.8$; $t$-test, $P<0.001$ ) and their distribution (numbers in ordinate identify bins for quantification; $t$-test, $P<0.001$; error bars indicate SEM). $(J-M) \mathrm{Nrg} 1$ expression in the ventricular zone is not altered in either Tbr2 mutant or control cortices ( $L, M$ are magnifications of $J, K$, respectively). ( $N-Q)$ Cxcl12 transcripts are selectively lost in the SVZ, but not MZ, cortical domain in Tbr2 mutant brains $(P, Q$ are magnifications of $N, O$, respectively). Bars: $A, D, J, 200 \mu \mathrm{m} ; G, L, 100 \mu \mathrm{m}$.

We then analyzed interneurons with regard to their birth date, and, consequently, their different dynamics of cortical invasion. Nonetheless, early as well as late originated interneurons, as identified by BrdU incorporation at either E12 or E15, were reduced at comparable levels in the E18.5 mutant with respect to control cortices (Supplemental Fig. S5).

Subpallial neurons are dispersed throughout the cortical tissue by extensive tangential migration occurring along the MZ and SVZ/IZ pathways with similar dynamics. Since Tbr2 mutant cortices have a dramatic decrease of the SVZ/IZ pathway, we wondered whether the absence of this pathway could affect the final settlement of interneurons, and thereby alter their laminar positioning. Surprisingly, we observed only minor alterations in the general distribution of interneurons, accounting for a statistically significant mislocalization of the Somatostatin ${ }^{+}$ interneurons, while all of the other subclasses displayed a normal cortical distribution (Fig. 2). This finding implies that unrecognized mechanisms might compensate for even severe alterations in the tangential migration pattern of the subpallial cells.

If loss of GABAergic inhibitory interneurons is balanced with a comparable decrease in excitatory glutamatergic neurons, it is predictable that the overall inhibitory tone should be sufficient to restrain cortical overexcitation. Accordingly, Tbr2 mutant animals never displayed a seizure-like behavior, either in the rest state or under stress conditions such as noise, repetitive handling, or hyperthermia. Furthermore, adult young mutants $(n=7)$ did not exhibit an increased susceptibility to the convulsant pentylenetetrazol (PTZ) compared with matching control animals $(n=7)$ (see the Materials and Methods). Finally, no changes were observed in 6-wk-old mutant animals $(n=3)$ in the expression domain of the immediate early gene $c$-Fos, which is normally associated with epileptic-like behavior (data not shown).

We next investigated how loss of INPs might cause such a dramatic alteration of interneuron migration. Multiple factors have been identified that influence interneuron 


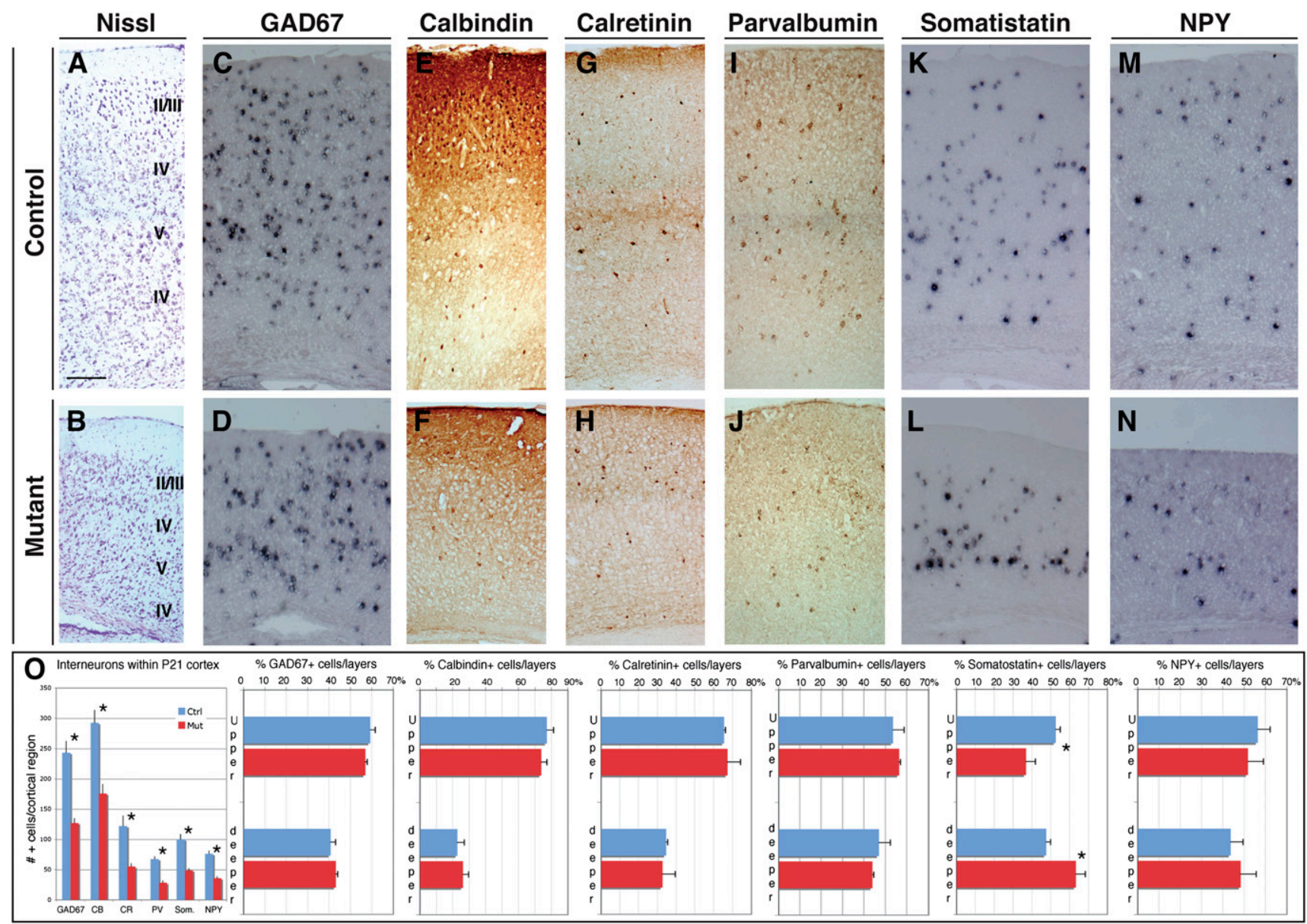

Figure 2. Postnatal Tbr2-deficient cortices have a reduced number of interneurons. $(A, B)$ Nissl staining of P21 Tbr2 mutant and control cortical walls. $(C-L)$ Immunohistochemistry or in situ hybridization for the pan-GABAergic marker GAD67 $(C, D)$, and markers of interneurons subclasses Calbindin $(E, F)$, Calretinin $(G, H)$, Parvalbumin $(I, J)$, Somatostatin $(K, L)$, and NPY $(M, N)$. A strong reduction is evident in the cortical GABAergic neurons in the mutant compared with the control cortices, although their general distribution throughout the cortical tissue was only marginally affected. (O) Quantification of total cells positive for each marker per field \pm SEM (Calbindin: Ctrl, $292.5 \pm 25.5$, Mut, $175.7 \pm 14.9$; Calretinin: Ctrl, $121.8 \pm 16.7$, Mut, $55.2 \pm$ 4.9; GAD67: Ctrl, $242.5 \pm 19$, and Mut, $126.8 \pm$ 7.6; Parvalbumin: Ctrl, $67.3 \pm 4.2$, and Mut, $28.2 \pm 4.4$; Somatostatin: Ctrl, $100.1 \pm 8.1$, and Mut, $48.7 \pm 2.94$; and NPY: Ctrl, $76.2 \pm 4.7$, and Mut, $35.7 \pm 2.9$; $t$-test, $P<0.001$ ) and their distribution within the CP between upper (II, II, and IV) and deeper (V and VI) layers; $\left({ }^{\star}\right) t$-test, $P<0.001$; error bars indicate SEM. Bar: $A, 200 \mu \mathrm{m}$.

migration at different levels, among which Neuregulin-1 (NRG1) and chemokine CXCL12 signaling play an important role in promoting interneuron migration (Stumm et al. 2003; Flames et al. 2004; Li et al. 2008; López-Bendito et al. 2008). At mid-embryogenesis (E14.5), when interneuron migration is massive, we found Nrg1 expression in the ventricular proliferative zone, and its levels were not altered in Tbr2 mutant embryos (Fig. 1J-M). On the contrary, at the same embryonic stage, Tbr2 mutants revealed a complete loss of Cxcl12 expression within the SVZ/IZ migratory cells (Fig. 1N-Q, arrowheads), whereas its expression in the superficial meningeal membranes was not altered (Fig. 1N-Q, arrows). Specific loss of Cxcl12 expression in the deep migration path also persisted for the successive embryonic development (Supplemental Fig. S2G-L). Accordingly, double labeling of Tbr2/Cxcl12 in normal embryos clearly showed that $C x c 112$ is coexpressed with Tbr2 in almost all cells of the SVZ, while the Nrg1 expression domain was mostly confined in the lower ventricular zone (Supplemental Fig. S6). These results indicate that INPs may be a unique source of Cxcl12 expression, which, in combination with other unknown factors, may promote interneuron migration in the SVZ compartment.

We reported previously that Tbr2 misexpression in the cortical ventricular layer via in utero eletroporation converts radial glial cells into INPs in a cell-autonomous manner (Sessa et al. 2008). We exploited this approach to generate ectopic INPs in the developing brain, and ascertained their effect on interneuron migration. Interestingly, the Tbr2-positive ectopic ventricular site accumulated Calbindin ${ }^{+}$interneurons $(23 \pm 6$ cells per section) (Fig. 3H, boxed area), which were not observed in equivalent sites misexpressing the GFP vector without showing an evident loss of Calbindin ${ }^{+}$cells in the $\mathrm{MZ}$ (Fig. 3A-H). Strikingly, the Tbr2 electroporated cells 
E15.5 (electroporated at E13.5)

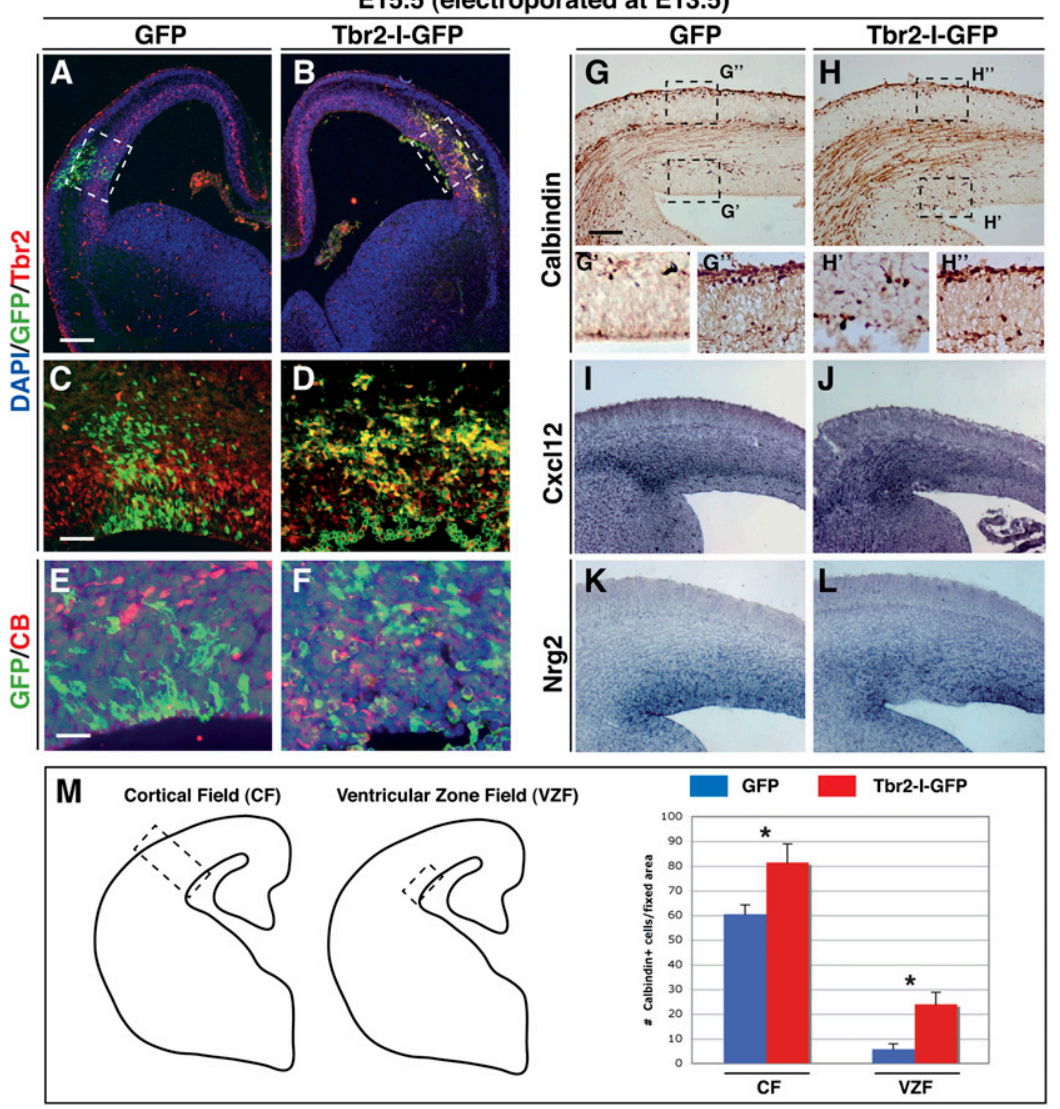

Figure 3. Tbr2-forced expression induces an ectopic source of chemoattraction for interneurons. $(A-D)$ Forced expression of GFP (control) or Tbr2ires-GFP in the ventricular region of the E13.5 wildtype cortices, analyzed after 2 d. $(E, F)$ Ectopic interneurons are not derived from electroporated cells, since GFP and Calbindin stainings are virtually exclusive. $(G, H)$ In the Tbr2-misexpressing region, but not the GFP-misexpressing region, we found an ectopic accumulation of Calbindin ${ }^{+}$interneurons (arrows in $H$, box $\left.H^{\prime}, G^{\prime}\right) .\left(G^{\prime \prime}, H^{\prime \prime}\right)$ The total amount of interneurons located in the $\mathrm{MZ}$ near the eletroporation sites is apparently unaffected by either GFP or Tbr2 misexpression. $(I-L)$ Up-regulation of Cxcl12 $(I, J)$ associated with Nrg1 down-regulation $(K, L)$ in the Tbr2 electroporated domain compared with controls. ( $M$ ) Quantification of Calbindin ${ }^{+}$cells in cortical field and ventricular zone field (see schema): CF gfp $=60.333 \pm 3.88 ; \mathrm{CF}$ tbr2 $=81.333 \pm 7.58 ;$ VZF gfp $=5.666 \pm 2.16 ;$ VZF tbr2 $\left.=23.833 \pm 4.87 .{ }^{*}\right) P<0.001$; error bars indicate SEM. Bars: $A, 200 \mu \mathrm{m} ; G, 150 \mu \mathrm{m} ; C, 100$ $\mu \mathrm{m} ; E, 50 \mu \mathrm{m}$. expressed high levels of Cxcl12 and, concomitantly, lower levels of Nrg1 activity, consistent with their reverted INP cell fate (Fig. 3I-L). In an analogous approach, Cxcl12-forced expression was also sufficient to attract interneurons into ventricular ectopic sites $(25 \pm 6$ cells per section) (Fig. 4A-H, arrows).

We then sought to determine the long-term effect of a sustained expression of either Tbr2 or Cxcl12 gene after several days of cortical development. Therefore, we analyzed E18.5 cortices electroporated with either gene or the control GFP at E13.5. Interestingly, we found a consistent increase of Calbindin ${ }^{+}$GABAergic interneuron settled in the targeted area, and calculated $33 \%$ and $76 \%$ when Tbr2 or Cxcl12 was expressed as compared with GFP only, respectively (Supplemental Fig. S7).

These findings suggest that ectopic $\mathrm{Tbr}^{+}$INPs can promote cell migration by relying in part on the secretion the Cxcl12 chemoattract molecule, which has been shown previously to play a fundamental role in interneuron migration (Bagri et al. 2002; Li et al. 2008; LópezBendito et al. 2008). Direct evidence for this is the significant rescue of interneuron migration obtained upon Cxc112 misexpression in the Tbr2 mutant cortex (Fig. 4JO). In fact, forced expression of Cxcl12 by in utero electroporation in the E13.5 Tbr2 mutant cortices promoted a wide migration of Calbindin ${ }^{+}$interneurons within the $\mathrm{CP}$, as already evident at $2 \mathrm{~d}$ after Cxc112 misexpression (Fig. 4O, arrows).
However, ectopic Calbindin ${ }^{+}$interneurons might originate from aberrant radial migration or from defective tangential invasion of subpallial cells. To elucidate this issue, Tbr2 or Cxcl12 electroporated E13.5 cortices were sliced and cultured in vitro with or without the ganglionic eminences (Fig. 5). We found significant abnormal location of Calbindin ${ }^{+}$cells only when ventral telencephalic tissue was included in the slice, suggesting that the ectopically positioned interneurons originated from subpallial regions (Fig. 5H-S).

To further investigate this process, we conceived an ex vivo experimental approach in which the Tbr2-GFP or DsRed (control) electroporated cortical tissues were dissected and spaced equally between an explant of MGE, acting as a source of migrating interneurons, and thus creating a direct competitive assay for interneuron migration (Fig. 6A). In fact, two DsRed electroporated cortical fragments placed on either side of the MGE explant elicited an equivalent migration of cells when observed for $48 \mathrm{~h}$ in culture (Supplemental Fig. S8). In contrast, when Tbr2- and DsRed-expressing cortical explants were assessed on this assay, MGE cell migration evidently was biased toward the Tbr2-expressing tissue (Fig. 6B-B'"',D). Similarly, aggregates of pure $\mathrm{GFP}^{+}$INPs isolated from Tbr2-GFP transgenic animals attracted MGE cell migration more efficiently than did $\mathrm{GFP}^{-}$cortical cells (data not shown). To ascertain whether INP-dependent interneuron migration relies on the Cxcl12/Cxcr4-7 signaling, we performed a similar 
E15.5 (electroporated at E13.5)
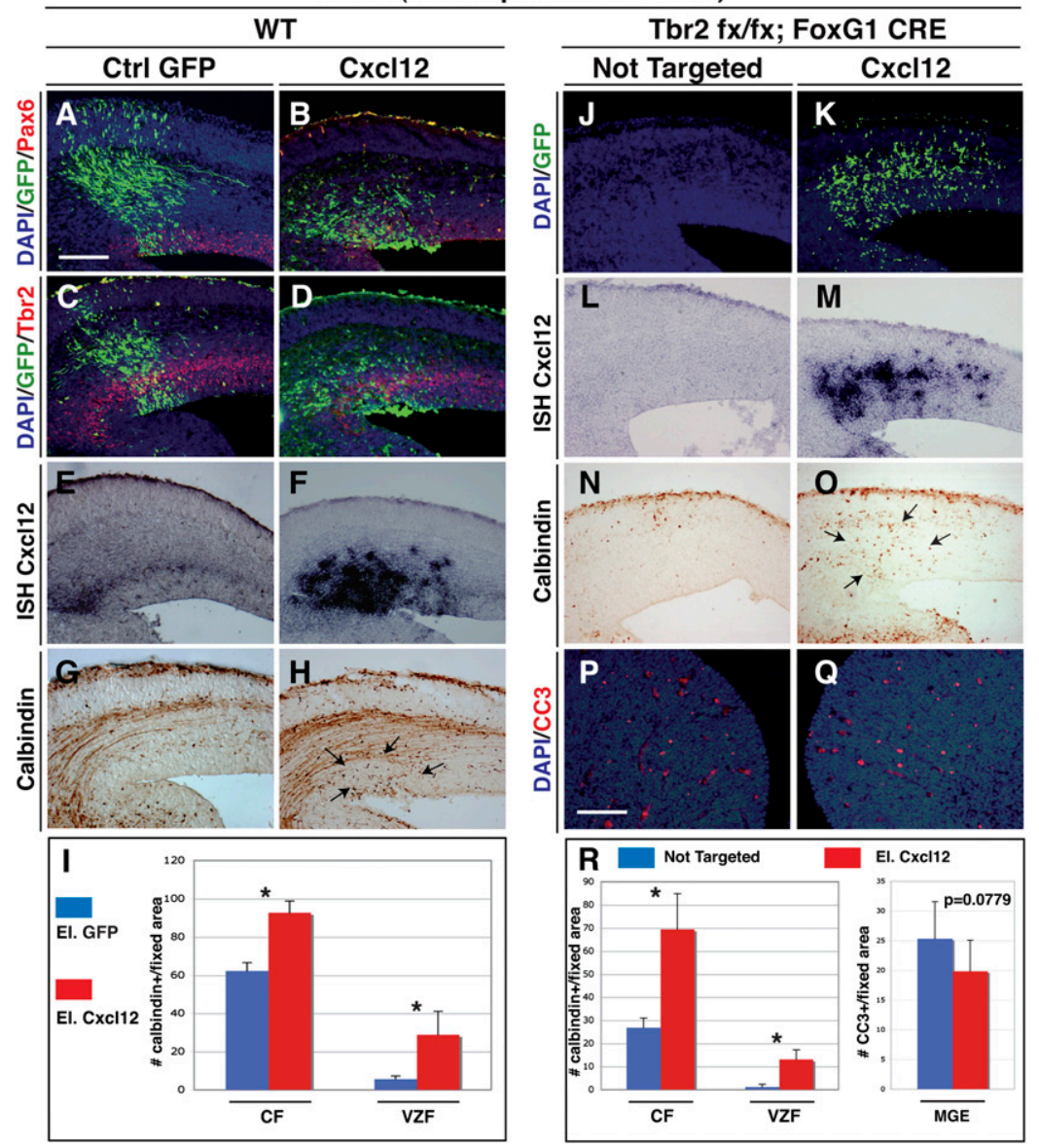

Figure 4. Cxcl12 ectopic expression induces accumulation of interneurons in the cortical $\mathrm{VZ}$ and rescues interneuron migration in Tbr2 mutant cortices. $(A-D)$ Immunofluorescence for Pax6 $(A, B)$ or Tbr2 $(C, D)$ (red) and GFP identifying the cortical domain electroporated with GFP-expressing (control) or Cxcl12-IRES-GFPexpressing vectors. $(E, F)$ Overexpression of Cxcl12 was confirmed by expression analysis. $(G, H)$ The Cxcl12-misexpressing cortical region displayed an evident accumulation of Calbindin ${ }^{+}$ interneurons ectopically localized in the VZ. $(I)$ Quantification of Calbindin ${ }^{+}$cells in cortical field and ventricular zone field: CF GFP = $62.166 \pm 4.26$; CF Cxcl12 = $88.5 \pm 3.94$; VZF $\mathrm{GFP}=5.5 \pm 1.76$; VZF Cxcl12 = $28.833 \pm 12.17$; error bars indicate SEM. $\left(^{*}\right) P<0.001 .(J, K)$ Immunofluorescence for GFP identifying the cortical domain electroporated with Cxcl12IRES-GFP-expressing vector $(K)$ compared with the nontargeted side in the controlateral hemisphere $(J)$ of the same Tbr2 mutant brain. $(L, M)$ In situ hybridization for Cxcl12 transcripts in the Tbr2 mutant brain, in either the control side (controlateral) $(L)$ or the other electoporated side $(M)$ of a Tbr2 mutant. $(N, O)$ Cxcl12 expression leads to a rescue of Calbindin ${ }^{+}$interneurons in the mutant cortex compared with the noneletroporated side. $(P, Q)$ Immunofluorescence for cleaved caspase III (CC3) identifying the cell death in MGE of the eletroporated side (Q) or the controlateral side $(P)$ of a Tbr2 mutant. $(R)$ Quantification of Calbindin ${ }^{+}$cells in cortical field and ventricular zone field and CC3 in MGE. Calbindin: CF NotTarg $=26.833 \pm 4.17$; CF Cxcl12 = $69.333 \pm 15.474 ;$ VZF NotTarg = $1.166 \pm 1.17$; VZF cxcl12 = $13 \pm 4.24$; error bars indicate SEM. $\left(^{\star}\right) P<0.001$. CC3: NotTarg MGE $=25.333 \pm 6.22 ;$ Cxcl12 MGE $=19.833 \pm$ 5.27; error bars indicate SEM. $P=0.0779$. Bars: $A, 100 \mu \mathrm{m} ; P, 200 \mu \mathrm{m}$.

assay and added into the culture medium a selective inhibitor of this molecular pathway (AMD3100) (Li et al. 2008; López-Bendito et al. 2008). Notably, we observed in these conditions a striking reduction in the preferential migration toward the Tbr2 rather than toward the DsRed electroporated cortical explants (Fig. 6C,D). However, we still noted more cases in which migration was biased toward the Tbr2-misexpressing tissue, suggesting that cell attraction could be mediated by other yet unknown factors expressed by INPs (Fig. 6D). Accordingly, in the Cxcl12 mutant brains, cortical interneurons are only partly affected, indicating that compensatory mechanisms are sufficient to sustain some tangential interneuron migration toward the cortex (Stumm et al. 2003).

\section{Discussion}

Taken together, our results establish that $\mathrm{Tbr}^{+}{ }^{+}$INPs are a source of chemoattractants, which generate a defined route in the cortical SVZ for sustained migration of subpallial interneurons. The SVZ is a tangential compartment that overlays the germinative layer constituted by radially packed proliferating glial cells. In contrast, INPs have a pronounced multipolar shape, with rather long neurites forming a cellular web-like structures (Noctor et al. 2004; Götz and Huttner 2005; Kowalczyk et al. 2009). Therefore, it is reasonable that the SVZ represents an amenable territory for active migration of tangentially oriented GABAergic interneurons, offering enough extracellular spaces for their long remarkable traveling. Tangential cell migration would be more difficult in the germinative layer (below the SVZ) or the CP (above the SVZ), which are constituted by packed radial-oriented proliferating and closely associated differentiated cells, respectively. Thus, INPs not only stimulate migration through the releasing of chemoattracts such as Cxcl12, but offer an ideal extracellular environment for longdistance cell migration.

Our findings are consistent with a previous work by Tiveron et al. (2006), who characterized Cxcl12 expression in the developing cortex. However, this analysisemploying conditional mouse mutants coupled with in vivo gain-of-function approaches, as well as ex vivo explant manipulations-establishes the role played by Cxc112-expressing $\mathrm{Tbr}^{+}$INPs in orchestrating subpallial interneuron attraction into the cortex. Nonetheless, our ex vivo experiments also indicate that INPs are the source of other unknown secreted factors as well. 


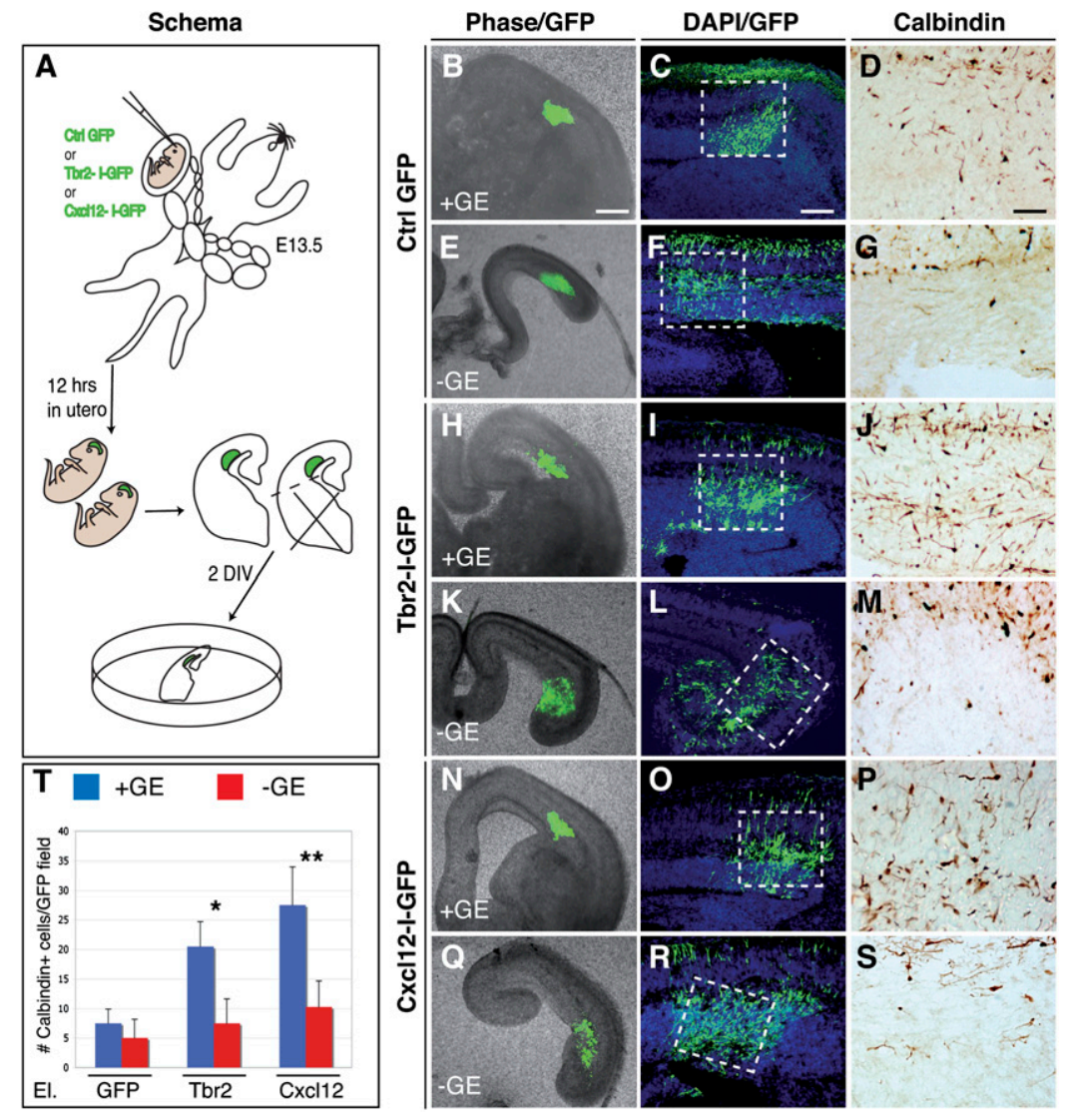

Figure 5. Accumulated interneurons in Tbr2misexpressing areas are derived from ganglionic eminences by tangential migration. $(A)$ Outline of the ex vivo experiment in which GFP, Tbr2-I-GFP, or Cxcl12-I-GFP electroporated brains were sliced $12 \mathrm{~h}$ after in utero eletroporation and cultured for $2 \mathrm{~d}$ in vitro, maintaining or removing the ganglionic eminences. $(B-G)$ In GFP electroporated cortices (control), none or very few Calbindin ${ }^{+}$cells are present regardless of whether ganglionic eminences are kept or removed. $(H-S)$ In contrast, many Calbindin ${ }^{+}$interneurons are accumulated in the Tbr2-I-GFP $(H-I)$ or Cxcl12-I-GFP $(N-P)$ electroporated cortical region of those brain slices that include the ganglionic eminences. $(K-M, Q-S)$ This cellular migration does not occur when ganglionic eminences are removed from the brain slices. (T) Quantification of Calbindin ${ }^{+}$cells in an electroporated field: GFP + GE $=7.5 \pm 2.38$; $\mathrm{GFP}-\mathrm{GE}=5 \pm 3.16$; Tbr $2+\mathrm{GE}=20.5 \pm 4.2$; Tbr2 $-\mathrm{GE}=7.5 \pm 4.12 ; \mathrm{Cxcl} 12+\mathrm{GE}=27.5 \pm$ 6.45; Cxcl12 - GE = $10.25 \pm 4.42$; error bars indicate SEM. $\left(^{\star}\right) P<0.001 ;\left(^{\star \star}\right) P<0.01$. Bars: $B, 250 \mu \mathrm{m} ; C, 150 \mu \mathrm{m} ; D, 50 \mu \mathrm{m}$.
We propose that INPs elicit the expansion of glutamatergic neurons, and simultaneously increase the amount of inhibitory interneurons that should invade the cortex in order to maintain the correct ratio between these two neuronal pools. This hypothesis suggests that the coordination between the expansion of the excitatory and inhibitory neuronal pools might be controlled strictly by INPs through two independent, albeit complementary, mechanisms. In brain evolution, the emergence of Tbr2 ${ }^{+}$ INPs in mammals is believed to have sustained the expansion of a six-layered cortex, starting from a small cortical field organized in three layers, as is found in reptiles and birds (Fig. 7; Cheung et al. 2007). This cortical expansion requires a comparable increase in inhibitory cells, which, in compliance with the ability of INPs to recruit interneurons, create a new route of tangential migration located in the SVZ (Fig. 7). Therefore, this model predicts that the more INPs generate excitatory neurons, the stronger the chemoattractant signal that recruits subpallial inhibitory interneurons. In this way, it generates a reciprocal regulatory loop, which intrinsically balances the two neuronal pools-a scenario that likely happened during the constant expansion of the cerebral cortex in mammalian evolution (Fish et al. 2008). In support of this theory, Tbr2 mutant cortices have been found to display an extremely reduced cerebral cortex, but to contain balanced numbers of excitatory and inhibitory neurons (Arnold et al. 2008; Sessa et al. 2008).
Similarly, microcephaly caused by inactivation of the TBR2 human homolog is not associated with epileptic seizures, indicating that the ratio between glutamatergic and GABAergic neurons is preserved (Baala et al. 2007). Interestingly, even primary microcephalic syndromes (MCPHs), whose origins are rooted in a proliferation defect in the radial glia cortical progenitors, are only rarely associated with severe epileptic seizures (Bond et al. 2005; Fong et al. 2008; Tibelius et al. 2009). This might be explained by the reduced number of INPs, as a consequence of a smaller pool of radial glial cells, which support the migration of only a minor fraction of subpallial GABAergic interneurons, balancing the ratio between glutamatergic and GABAergic neurons, and thereby their respective excitatory and inhibitory tones. In contrast, congenic cortical malformations associated with cell migration defects, like various forms of lissencephaly, are strongly associated with epilepsy or infantile spasms, which might result from the unbalanced loss of cortical GABAergic neurons prevented from reaching the cortex from the subpallium (Kato and Dobyns 2003; Kappeler et al. 2006; Kitamura et al. 2009). Thus, INPs are a crucial cellular hub connecting direct and indirect cortical expansion, and the tripartite layering organization of the developing cortex-with the VZ, SVZ, and CP-provides an ideal set of compartments where tangential migration can take place with minimal interference on local cell proliferation and differentiation. 

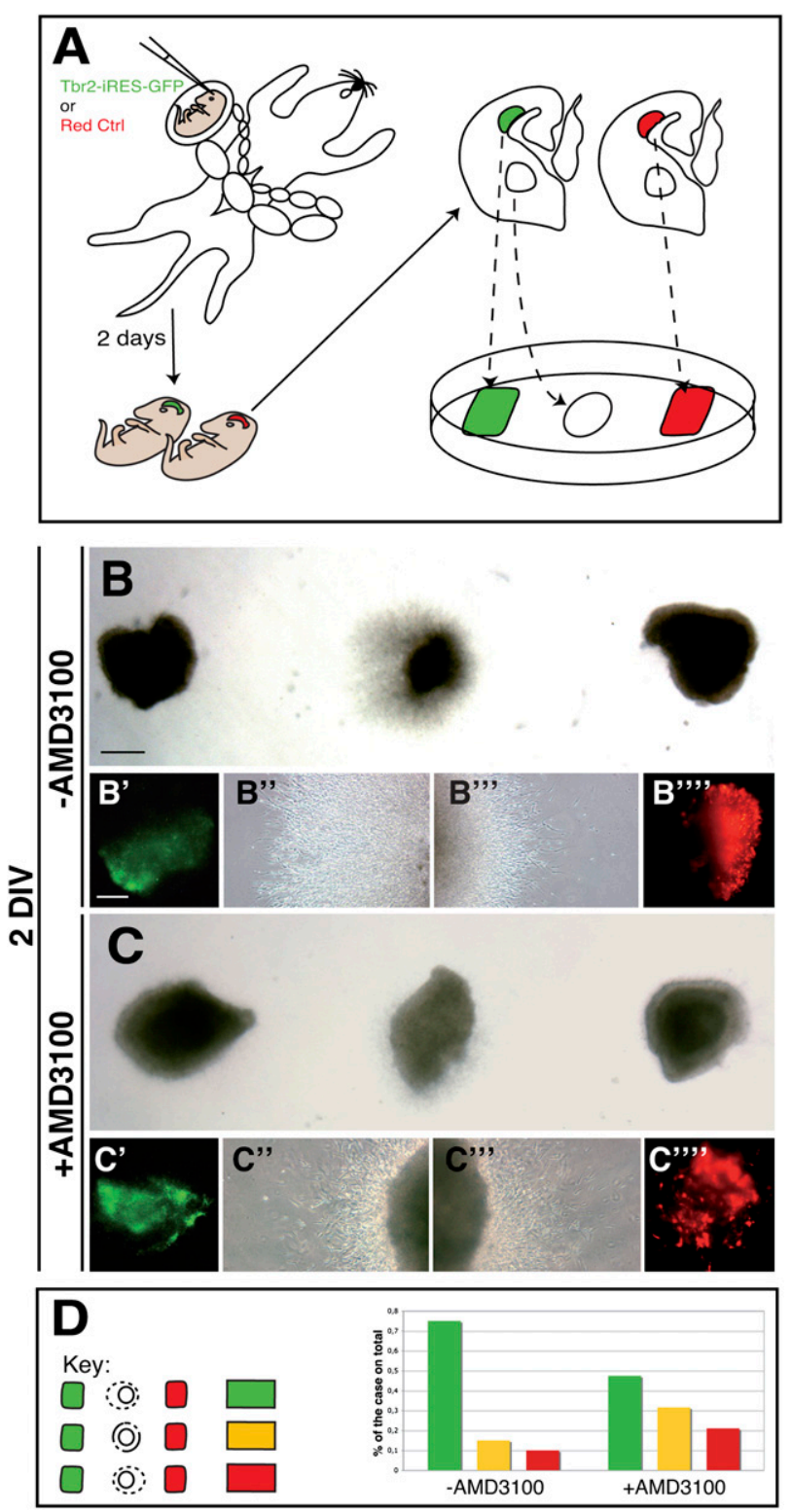

Figure 6. Tbr2 interneuron attractive activity is strongly dependent on Cxcl12 signaling. (A) Outline of the ex vivo approach employing the electroporated cortical domains (red with control, green with $\mathrm{Tbr} 2$ ) as a chemoattractant source in competitive assay for migration of MGE-derived interneurons. $\left(B-B^{\prime \prime \prime}\right)$ Representative pictures of the competitive assays showing how Tbr2 electroporated explants are able to attract more MGE migrating cells with respect to the control. $\left(C-C^{\prime \prime \prime}\right)$ The supplementation of the Cxcl12 inhibitor AMD3100 $(100 \mu M)$ strongly attenuates Tbr2-dependent cell migration attraction. $(D)$ Classification by color code of the different experiments showing either biased migration toward the Tbr2-expressing (green) or the DsRed-expressing (red) explants, or comparable migration in either explant (yellow). Without AMD3100, 15 of 20 explants show a preferential migration toward the Tbr2 source, two of 20 show a preferential migration toward the DsRed source, and three of 20 do not display preferential direction. With AMD3100, nine of 19 migrate preferentially toward the Tbr2 source, four of 19 migrate preferentially toward the DsRed source, and six of 19 do not show any preference in migration orientation. Bars: $B, 100 \mu \mathrm{m} ; B^{\prime}, 50 \mu \mathrm{m}$.

\section{Materials and methods}

\section{Animals}

Tbr2 conditional mutant mice (Tbr2 $2^{\text {flox/flox }}$ (Mao et al. 2008) were maintained by backcrossing them with $\mathrm{C} 57 \mathrm{Bl} / 6$ animals. To inactivate Tbr2 in the developing forebrain, Tbr2 flox/flox mice were crossed with Tbr2 $2^{\Delta f l o x /+}$; Foxg1-cre animals (Hébert and McConnell 2000). Genotyping to distinguish wild-type, floxed, and deleted Tbr2 alleles was performed as described previously (Mao et al. 2008). BAC transgenic Tbr2::GFP (Eomes::GFP,) mice were kindly provided by Anna-Katerina Hadjantonakis (Sloan-Kettering Institute, New York) (Kwon and Hadjantonakis 2007). Mice were maintained at San Raffaele Scientific Institute Institutional mouse facility, and experiments were performed in accordance with experimental protocols approved by local institutional animal care and use committees (IACUCs).

\section{In situ RNA hybridization (ISH)}

ISHs on frozen sections were performed as described previously by Schaeren-Wiemers and Gerfin-Moser (1993) with the following modifications. Sections were fixed for $30 \mathrm{~min}$ at room temperature in $4 \%$ paraformaldeyde in $\mathrm{PBS}$, and were treated for $5 \mathrm{~min}$ with $1 \mu \mathrm{g} / \mathrm{mL}$ proteinase $\mathrm{K}$ in $1 \mathrm{mM}$ EDTA, and $20 \mathrm{mM}$ Tris- $\mathrm{HCl}(\mathrm{pH}$ 7.0). Prior to hybridization, they were washed twice in $2 \times \mathrm{SSC}$ for $15 \mathrm{~min}$, and incubated in $0.1 \mathrm{M}$ Tris/0.1 M glycine for at least $30 \mathrm{~min}$. The hybridization solution (60 $\mu \mathrm{L}$ per slide) contained $50 \%$ formamide, $5 \times \mathrm{SSC}(\mathrm{pH}$ adjusted with citric acid to $\mathrm{pH} 6.0$ ), $5 \%$ dextran sulfate, $2 \mathrm{mg} / \mathrm{mL}$ heparin, $100 \mu \mathrm{g} / \mathrm{mL}$ tRNA, and from 1:100 to 1:50 dilution of the riboprobes, and was performed overnight at $65^{\circ} \mathrm{C}$ using coverslips. Next, the sections were washed for $1-2 \mathrm{~h}$ in $0.5 \times \mathrm{SSC}$ and $20 \%$ formamide at $65^{\circ} \mathrm{C}$. Subsequently, they were treated with $10 \mu \mathrm{g} / \mathrm{mL}$ RNaseA for 30 min at $37^{\circ} \mathrm{C}$ in NTE, then washed for $4 \mathrm{~h}$ in $0.5 \times$ SSC and $20 \%$ formamide at $65^{\circ} \mathrm{C}$ and for $30 \mathrm{~min}$ in $2 \times \mathrm{SSC}$, and blocked for $1 \mathrm{~h}$ at room temperature in $1 \%$ blocking reagent (Roche) in MABT. A 1:5000 dilution of anti-digoxigenin AP-conjugated antibody (Roche) was preincubated for at least $1 \mathrm{~h}$ in $1 \%$ blocking reagent in MABT at $4^{\circ} \mathrm{C}$. Slices were incubated with the antibody overnight at $4^{\circ} \mathrm{C}$, washed for $6 \mathrm{~h}$ in TBST and for $30 \mathrm{~min}$ in NTMT, and stained using centrifuged BM purple AP substrate (Roche) in $0.3 \%$ Tween- 20 for $12-36 \mathrm{~h}$ at $4^{\circ} \mathrm{C}$ or room temperature. Slices were washed in NTMT, then in distilled water, and were mounted in Aquamount (Polysciences). The following probes were used: Cxcl12 (kind gift of Oscar Marin), Nrg1, Somatostatin, NPY, Lhx6 (kind gift of Vassilis Pachinis), GAD67, and Reelin.

\section{Immunohistochemistry}

Immunohistochemical analyses were performed as described previously (Colombo et al. 2004). Briefly, frozen or paraffin sections were boiled in $10 \mathrm{mM}$ sodium citrate $(\mathrm{pH}$ 6.0) and blocked in 10\% NGS (normal goat serum) and $0.2 \%$ Triton-X-100 for $1 \mathrm{~h}$ at room temperature. Incubation with primary antibodies was performed overnight at $4^{\circ} \mathrm{C}$. Secondary antibodies were applied to sections for $2 \mathrm{~h}$ at room temperature. The primary antibodies used were as follows: rabbit anti-Tbr2 (1:200; Chemicon), rabbit anti-Calbindin (1:500; Swant), rabbit anti-Calretinin (1:300; Chemicon), rabbit anti-Pax6 (1:200; Covance), rabbit anti-Lhx6 (1:50; kindly provided by Vassilis Pachnis), monoclonal anti-GFP (1:300; Invitrogen), rabbit anti-GFP (1:500; Invitrogen). Secondary antibodies were conjugates of Alexa Fluor 488, Alexa Fluor 594, and Alexa Fluor 647 (1:500) or biotin (1:200). DAPI $\left(4^{\prime}, 6^{\prime}\right.$-diamidino-2-phenylindole) was used as nuclear counterstaining. Finally, slices were washed and mounted in Fluorescent Mounting Medium (Dako Cytomation). 


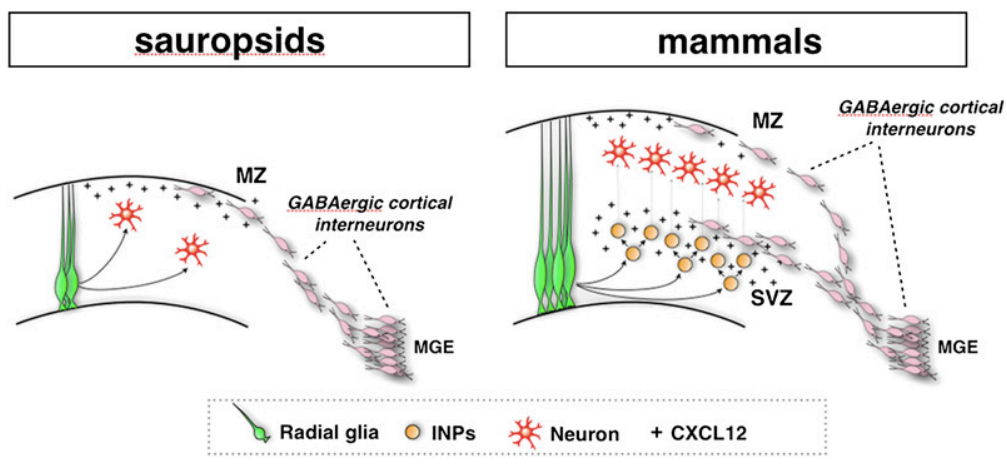
Cxcl12, giving rise to a supplementary tangential route of migration over the SVZ compartment.

\section{In utero electroporation}

Tbr2 (kind gift from J. Rubenstein and A. Bulfone) and Cxcl12 coding sequences (kind gift from O. Marin) were cloned in the pCAG expression vector upstream of an ires-EGFP cassette (Niwa et al. 1991). Electroporation was used to deliver expression vectors to the ventricular RGCs in utero as described previously (Gal et al. 2006; Saito 2006). Briefly, uterine horns of E12.5 or E13.5 pregnant dams were exposed by midline laparotomy after anesthetization with Avertin $(312 \mathrm{mg} / \mathrm{kg})$. One microliter of DNA plasmid corresponding to $3 \mu \mathrm{g}$ mixed with $0.03 \%$ fastgreen dye in PBS was injected in the telencephalic vesicle using a pulled micropipette through the uterine wall and amniotic sac. Seven-millimeter platinum tweezer-style electrodes were placed outside the uterus over the telencephalon, and four pulses of 42 $\mathrm{V}$ were applied at $40-\mathrm{msec}$ intervals by using a BTX square wave electroporator. The uterus was then replaced in the abdomen, the cavity was filled with warm sterile PBS, and the abdominal muscle and skin incisions were closed with silk sutures.

\section{Organotypic culture}

Slice cultures of E14.5 embryonic mouse forebrain were prepared as described previously, starting from brains electroporated in utero $12 \mathrm{~h}$ before with GFP alone or Tbr2-ires-GFP (Anderson et al. 1997). Briefly, mouse brains were isolated and embedded in $4 \%$ low-melting agarose (Sigma), and $250-\mu \mathrm{m}$-thick coronal sections were cut using a vibratome (VT1100, Leica). The sections-either whole or after manual dissection of ventral telencephalon-were then transferred to polycarbonate culture membranes (diameter, $13 \mathrm{~mm}$; pore size, $8 \mu \mathrm{m}$; Costar) in organ tissue dishes containing $1.5 \mathrm{~mL}$ of serum-containing medium (Gibco a-MEM with $10 \%$ fetal calf serum, glutamine, penicillin, streptomycin). Slices were maintained for $1 \mathrm{~h}$ at $37^{\circ} \mathrm{C}$ in $5 \% \mathrm{CO}_{2}$ in a standard sterile incubator before changing to the Neurobasal/B27 (Gibco) medium. The cultures were maintained for $2 \mathrm{~d}$ in vitro and then fixed in 4\% PFA overnight before inclusion and cryosectioning.

\section{Competitive migration assay}

MGE explants were dissected out from wild-type E14.5 organotypic brain slices, while dsRed- and Tbr2-ires-GFP-misexpressed cortical explants were dissected from the whole brains $12 \mathrm{~h}$ after in utero electroporation. The explants were positioned in the same Matrigel drop in the following way: MGE explant was put in between dsRed and Tbr2-ires-GFP electroporated cortical
Figure 7. Model of cortical evolution based on INP function. (Left) During cortical development in the sauropsids (reptile and birds), glutamatergic neurons originate from direct differentiation of radial glia cells, while cortical GABAergic interneurons derive from the MGE in ventral telencephalon. Interneuron migration follows mainly a tangential stream coinciding with the MZ, probably sustained by superficial meningeal membranes secreting at least Cxcl12. (Right) In developing mammalian cortices, a large number of INPs arises to constitute the SVZ, which promotes the expansion of the excitatory neuronal pool and results in a larger and thicker cerebral cortex organized in six layers. To keep the functional balance
GABAergic interneurons, through at least expression of

xplants (or two dsRed as control). The explants were cultured for $2 \mathrm{~d}$ in Neurobasal/B27 (Gibco) medium with or without the Cxcl12/Cxcr4 signaling inhibitor AMD3100 (100 $\mu \mathrm{M})$. The quantification was made as the percentage of the cases in which the MGE-derived interneurons were attracted preferentially toward one cortical explant (dsRed or Tbr2-ires-GFP), or no difference between the two sides was shown.

\section{Behavior analysis}

Tbr2 ${ }^{\Delta f l o x /+}$; Foxg1-cre mutant mice were viable and had normal appearance at birth, but were generally smaller than their littermates and died within 5-7 wk after birth. Mutant mice were hypotonic with evident locomotor deficits, but never displayed evident tremors or epileptic-like behavior either in rest state or exposed to stressful conditions (noise, repetitive handling, or hyperthermia). No changes were observed in 6-wk-old mutant animals $(n=3)$ in the expression domain of the immediate early gene c-Fos, which is normally associated with epileptic-like behavior. Then, 4-wk-old mutant and control mice (seven mutants and seven wild-type littermate mice, all males) were assessed for susceptibility when challenged with the convulsant PTZ, a GABA antagonist. A single injection of PTZ at a dose of 50 $\mathrm{mg} / \mathrm{kg}$ was administered subcutaneously, and animals were monitored for the following $30 \mathrm{~min}$. Behavioral response was scored using a rating system applied to the five-stage scale described by Racine (1972). In neither case did animals develop generalized tonic-clonic seizures, whereas they both displayed comparable stage III seizures with a benign type of course. Two control and three mutant mice did not develop evident seizures during the observation period. The seizure severity data were analyzed for significance with an ANOVA test.

\section{Quantification and statistical analysis}

At least three serial sections from three different animals for each genotype were photographed using a Nikon Eclipse 600 fluorescent microscope. Images were imported into Photoshop CS3. EGFP-only, marker-only, and/or double-positive cells were overlaid manually by color-coded dots in new layers. The number of labeled cells (dots) was calculated using the record measurements of Photoshop CS3 and was imported into Excel 2008. The total number of labeled cells per field per section was calculated across all brains. Results were expressed as the mean value of marker ${ }^{+}$ cells per field \pm SEM, and were tested for statistical significance by the one-tailed Student's $t$-test for paired differences with GraphPad Prism software. For the distribution of the marker ${ }^{+}$cells in the 
cortical wall, the entire coronal section of the cortex was divided arbitrarily in four, six, or eight bins (according to the developmental stage), and positive cells were counted per bin. Results were expressed as the percentage of the marker ${ }^{+}$cells per bin on total marker ${ }^{+}$cells per section, and were tested for statistical significance by the one-tailed Student's $t$-test for paired differences with GraphPad Prism software.

\section{Acknowledgments}

We are grateful to V. Pachnis and O. Marin for Lhx6 and Cxcl12 in situ probes, respectively. We acknowledge Michèle Studer, Antonello Mallamaci, Vassilis Pachnis, and members of Broccoli's laboratory for fruitful discussion. This study was funded by grants from Telethon (GGP81071) and Italian Ministry of Health (Young Research Award) to V.B., and from the National Eye Institute (EY011930 and EY010608-139005) and the Robert A. Welch Foundation (G-0010) to W.H.K.

\section{References}

Anderson SA, Qiu M, Bulfone A, Eisenstat DD, Meneses J, Pedersen R, Rubenstein JL. 1997. Mutations of the homeobox genes Dlx-1 and Dlx-2 disrupt the striatal subventricular zone and differentiation of late born striatal neurons. Neuron 19: $27-37$.

Arnold SJ, Huang GJ, Cheung AF, Era T, Nishikawa S, Bikoff EK, Molnár Z, Robertson EJ, Groszer M. 2008. The T-box transcription factor Eomes/Tbr2 regulates neurogenesis in the cortical subventricular zone. Genes Dev 22: 2479-2484.

Baala L, Briault S, Etchevers HC, Laumonnier F, Natiq A, Amiel J, Boddaert N, Picard C, Sbiti A, Asermouh A, et al. 2007. Homozygous silencing of T-box transcription factor EOMES leads to microcephaly with polymicrogyria and corpus callosum agenesis. Nat Genet 39: 454-456.

Bagri A, Gurney T, He X, Zou YR, Littman DR, Tessier-Lavigne M, Pleasure SJ. 2002. The chemokine SDF1 regulates migration of dentate granule cells. Development 129: 4249-4260.

Batista-Brito R, Fishell G. 2009. The developmental integration of cortical interneurons into a functional network. Curr Top Dev Biol 87: 81-118.

Belforte JE, Zsiros V, Sklar ER, Jiang Z, Yu G, Li Y, Quinlan EM, Nakazawa K. 2010. Postnatal NMDA receptor ablation in corticolimbic interneurons confers schizophrenia-like phenotypes. Nat Neurosci 13: 76-83.

Bond J, Roberts E, Springell K, Lizarraga SB, Scott S, Higgins J, Hampshire DJ, Morrison EE, Leal GF, Silva EO, et al. 2005. A centrosomal mechanism involving CDK5RAP2 and CENPJ controls brain size. Nat Genet 37: 353-355.

Cheung AF, Pollen AA, Tavare A, DeProto J, Molnár Z. 2007. Comparative aspects of cortical neurogenesis in vertebrates. I Anat 211: 164-176.

Colombo E, Galli R, Cossu G, Gécz J, Broccoli V. 2004. Mouse orthologue of ARX, a gene mutated in several X-linked forms of mental retardation and epilepsy, is a marker of adult neural stem cells and forebrain GABAergic neurons. Dev Dyn 231: 631-639.

Farkas LM, Huttner WB. 2008. The cell biology of neural stem and progenitor cells and its significance for their proliferation versus differentiation during mammalian brain development. Curr Opin Cell Biol 20: 707-715.

Farkas LM, Haffner C, Giger T, Khaitovich P, Nowick K, Birchmeier C, Pääbo S, Huttner WB. 2008. Insulinomaassociated 1 has a panneurogenic role and promotes the generation and expansion of basal progenitors in the developing mouse neocortex. Neuron 60: 40-55.
Fish JL, Dehay C, Kennedy H, Huttner WB. 2008. Making bigger brains-the evolution of neural-progenitor-cell division. J Cell Sci 121: 2783-2793.

Flames N, Long JE, Garratt AN, Fischer TM, Gassmann M, Birchmeier C, Lai C, Rubenstein JL, Marín O. 2004. Shortand long-range attraction of cortical GABAergic interneurons by neuregulin-1. Neuron 44: 251-261.

Fong KW, Choi YK, Rattner JB, Qi RZ. 2008. CDK5RAP2 is a pericentriolar protein that functions in centrosomal attachment of the $\gamma$-tubulin ring complex. Mol Biol Cell 19: 115-125.

Gal JS, Morozov YM, Ayoub AE, Chatterjee M, Rakic P, Haydar TF. 2006. Molecular and morphological heterogeneity of neural precursors in the mouse neocortical proliferative zones. J Neurosci 26: 1045-1056.

Götz M, Huttner WB. 2005. The cell biology of neurogenesis. Nat Rev Mol Cell Biol 6: 777-788.

Hébert JM, McConnell SK. 2000. Targeting of cre to the Foxg1 (BF-1) locus mediates loxP recombination in the telencephalon and other developing head structures. Dev Biol 222: 296-306.

Kalanithi PS, Zheng W, Kataoka Y, DiFiglia M, Grantz H, Saper CB, Schwartz ML, Leckman JF, Vaccarino FM. 2005. Altered parvalbumin-positive neuron distribution in basal ganglia of individuals with Tourette syndrome. Proc Natl Acad Sci 102: 13307-13312.

Kappeler C, Saillour Y, Baudoin JP, Tuy FP, Alvarez C, Houbron C, Gaspar P, Hamard G, Chelly J, Métin C, et al. 2006. Branching and nucleokinesis defects in migrating interneurons derived from doublecortin knockout mice. Hum Mol Genet 15: 1387-1400.

Kato M, Dobyns WB. 2003. Lissencephaly and the molecular basis of neuronal migration. Hum Mol Genet 1: R89-R96. doi: $10.1093 / \mathrm{hmg} / \mathrm{ddg} 086$.

Kitamura K, Itou Y, Yanazawa M, Ohsawa M, Suzuki-Migishima R, Umeki Y, Hohjoh H, Yanagawa Y, Shinba T, Itoh M, et al. 2009. Three human ARX mutations cause the lissencephalylike and mental retardation with epilepsy-like pleiotropic phenotypes in mice. Hum Mol Genet 18: 3708-3724.

Kowalczyk T, Pontious A, Englund C, Daza RA, Bedogni F, Hodge R, Attardo A, Bell C, Huttner WB, Hevner RF. 2009. Intermediate neuronal progenitors (basal progenitors) produce pyramidal-projection neurons for all layers of cerebral cortex. Cereb Cortex 19: 2439-2450.

Kwon GS, Hadjantonakis AK. 2007. Eomes:GFP-A tool for live imaging cells of the trophoblast, primitive streak, and telencephalon in the mouse embryo. Genesis 45: 208-217.

Kriegstein A, Noctor S, Martínez-Cerdeño V. 2006. Patterns of neural stem and progenitor cell division may underlie evolutionary cortical expansion. Nat Rev Neurosci 7: 883-890.

Li G, Adesnik H, Li J, Long J, Nicoll RA, Rubenstein JL, Pleasure SJ. 2008. Regional distribution of cortical interneurons and development of inhibitory tone are regulated by Cxcl12/ Cxcr4 signaling. J Neurosci 28: 1085-1098.

López-Bendito G, Sánchez-Alcañiz JA, Pla R, Borrell V, Picó E, Valdeolmillos M, Marín O. 2008. Chemokine signaling controls intracortical migration and final distribution of GABAergic interneurons. I Neurosci 28: 1613-1624.

Marín O, Rubenstein JL. 2001. A long, remarkable journey: Tangential migration in the telencephalon. Nat Rev Neurosci 2: $780-790$.

Mao CA, Kiyama T, Pan P, Furuta Y, Hadjantonakis AK, Klein WH. 2008. Eomesodermin, a target gene of Pou4f2, is required for retinal ganglion cell and optic nerve development in the mouse. Development 135: 271-280.

Molyneaux BJ, Arlotta P, Menezes JR, Macklis JD. 2007. Neuronal subtype specification in the cerebral cortex. Nat Rev Neurosci 8: 427-437. 
Niwa H, Yamamura K, Miyazaki J. 1991. Efficient selection for high-expression transfectants with a novel eukaryotic vector. Gene 108: 193-199.

Noctor SC, Martínez-Cerdeño V, Ivic L, Kriegstein AR. 2004. Cortical neurons arise in symmetric and asymmetric division zones and migrate through specific phases. Nat Neurosci 7: 136-144.

Pinto L, Drechsel D, Schmid MT, Ninkovic J, Irmler M, Brill MS, Restani L, Gianfranceschi L, Cerri C, Weber SN, et al. 2009. AP $2 \gamma$ regulates basal progenitor fate in a region- and layer-specific manner in the developing cortex. Nat Neurosci 12: 1229-1237.

Polleux F, Whitford KL, Dijkhuizen PA, Vitalis T, Ghosh A. 2002. Control of cortical interneuron migration by neurotrophins and PI3-kinase signaling. Development 129: 3147-3160.

Powell EM, Campbell DB, Stanwood GD, Davis C, Noebels JL, Levitt P. 2003. Genetic disruption of cortical interneuron development causes region- and GABA cell type-specific deficits, epilepsy, and behavioral dysfunction. I Neurosci 23: 622-631.

Racine RJ. 1972. Modification of seizure activity by electrical stimulation. II. Motor seizure. Clin Neurophysiol 32: 281294.

Saito T. 2006. In vivo electroporation in the embryonic mouse central nervous system. Nat Protoc 1: 1552-1558.

Schaeren-Wiemers N, Gerfin-Moser A. 1993. A single protocol to detect transcripts of various types and expression levels in neural tissue and cultured cells: In situ hybridization using digoxigenin-labelled cRNA probes. Histochemistry 100: 431-440.

Sessa A, Mao CA, Hadjantonakis AK, Klein WH, Broccoli V. 2008. Tbr2 directs conversion of radial glia into basal precursors and guides neuronal amplification by indirect neurogenesis in the developing neocortex. Neuron 60: 56-69.

Stumm RK, Zhou C, Ara T, Lazarini F, Dubois-Dalcq M, Nagasawa T, Höllt V, Schulz S. 2003. CXCR4 regulates interneuron migration in the developing neocortex. J Neurosci 23: 5123-5130.

Tibelius A, Marhold J, Zentgraf $\mathrm{H}$, Heilig CE, Neitzel $\mathrm{H}$, Ducommun B, Rauch A, Ho AD, Bartek J, Krämer A. 2009. Microcephalin and pericentrin regulate mitotic entry via centrosome-associated Chk1. J Cell Biol 185: 1149-1157.

Tiveron MC, Rossel M, Moepps B, Zhang YL, Seidenfaden R, Favor J, König N, Cremer H. 2006. Molecular interaction between projection neuron precursors and invading interneurons via stromal-derived factor 1 (CXCL12)/CXCR4 signaling in the cortical subventricular zone/intermediate zone. I Neurosci 26: 13273-13278.

Wonders C, Anderson SA. 2006. The origin and specification of cortical interneurons. Nat Rev Neurosci 7: 687-696. 


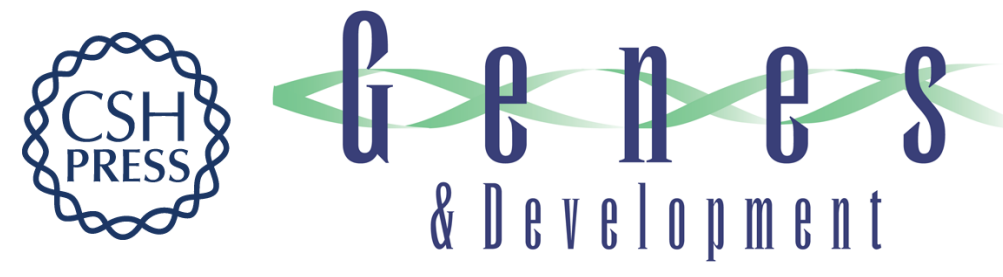

\section{Tbr2-positive intermediate (basal) neuronal progenitors safeguard cerebral cortex expansion by controlling amplification of pallial glutamatergic neurons and attraction of subpallial GABAergic interneurons}

Alessandro Sessa, Chai-An Mao, Gaia Colasante, et al.

Genes Dev. 2010, 24:

Access the most recent version at doi:10.1101/gad.575410

Supplemental
Material http://genesdev.cshlp.org/content/suppl/2010/08/11/24.16.1816.DC1

References This article cites 42 articles, 13 of which can be accessed free at: http://genesdev.cshlp.org/content/24/16/1816.full.html\#ref-list-1

License

Email Alerting Receive free email alerts when new articles cite this article - sign up in the box at the top Service right corner of the article or click here.

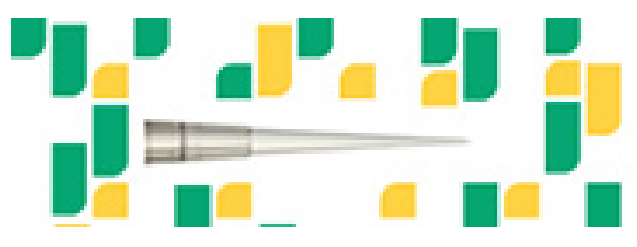

Focused on your science. 